\title{
Estimation of Exposure to Agent Orange and Other Defoliants Among American Troops in Vietnam: A Methodological Approach
}

\author{
Steven D. Stellman, PhD, and Jeanne M. Stellman, PhD
}

\begin{abstract}
Two pivotal problems in determining whether exposure to herbicides has caused disease in Vietnam veterans or their offspring are definition of which troops were exposed and extent of exposure. The DoD HERBS tape is the most complete publicly available record of herbicide spraying in Vietnam. It contains about 17,000 records consisting of coordinates of spray missions, dates, chemical agent, quantity and area sprayed, and mission purpose. We have developed a set of discrete and continuous indexes of probability of exposure to herbicides for individual veterans. These probability indexes are based on HERBS tape spray data and on locations and dates of service derived from a place-anddate matrix completed by the veteran. They can take into account a conservative estimate of environmental persistence of herbicide by using first-order exponential decay kinetics with an estimated half-life of dioxin. Mean values for the continuous exposure probability indexes were significantly greater among veterans judged to be exposed according to self-reported job titles and specific military experiences than among men judged unlikely to have been exposed. Probabilistic exposure indexes based on the HERBS tape for classification of likely exposure to herbicides in South Vietnam during 1965-1971 appear to be well suited for comparative classification of veterans and hence for use in epidemiologic studies.
\end{abstract}

Key words: Agent Orange, phenoxy herbicides, TCDD, dioxin, Vietnam veterans

\section{INTRODUCTION}

The possible human health effects associated with the systematic spraying of large portions of South Vietnam with defoliating chemicals carried out by the United States during 1962-1971 are a matter of great public and professional debate and concern. During that time, nearly 6 million acres of land were sprayed. Agent Orange, a 1:1 mixture of the n-butyl esters of 2,4-D and 2,4,5-T, was the main herbicide used. Agents White (2,4-D and picloram) and Blue (cacodylic acid) were also used but in lesser amounts [Young et al, 1978].

American Cancer Society, New York, New York (S.D.S.).

School of Public Health, Comprehensive Cancer Center, Columbia University, New York, New York (J.M.S.).

A preliminary account of this work was presented at the annual meeting of the American Public Health Association in Montreal, November, 1982.

Address reprint requests to Dr. Steven D. Stellman, American Cancer Society, 4 West 35th Street, New York, NY 10001.

Accepted for publication September 17, 1985.

(C) 1986 Alan R. Liss, Inc. 
The ingredients of Agent Orange are known to be toxic. 2,4,5-T is embryotoxic and teratogenic to the mouse [Courtney and Moore, 1971; Neubert and Dillmann, 1972; Hood et al, 1979], causes fetal anomalies in hamsters [Collins and Williams, 1971], and induces a variety of genotoxic effects in numerous animal and plant species [Grant, 1979]. 2,4-D in large doses can poison experimental animals and livestock [Rowe and Hymas, 1954; Fenton, 1984] and is neurotoxic to humans [Goldstein et al, 1959]. When given orally to rats, 2,4-D was found to be embryotoxic and fetotoxic but not teratogenic [Schwetz et al, 1971].

The 2,4,5-T used in Agent Orange was also heavily contaminated with 2,3,7,8tetrachloro-p-dibenzodioxin (TCDD) and its congeners [Young et al, 1978]. The mean concentration of TCDD in Agent Orange was $2 \mathrm{ppm}$. Individual concentrations ranged from 0.05 to about $30 \mathrm{ppm}$ [Young et al, 1978]. In laboratory animals, TCDD was found to be extremely toxic [Huff et al, 1980]. The LD50 for guinea pigs is less than $2 \mu \mathrm{g} / \mathrm{kg}$ of body weight [Huff et al, 1980; Schwetz et al, 1973]. At subacute doses, it produces many other systemic effects. TCDD is also embryotoxic and teratogenic to several strains of rats and mice [Courtney and Moore, 1971] and has been found to be carcinogenic by several routes of administration [International Agency for Research on Cancer, 1977; Van Miller et al, 1977; Kociba et al, 1978].

The effects of TCDD on humans are not so well established as those for animals. Human health effects are known chiefly from studies following industrial accidents and other occupational exposures. Clinical evaluation of workers and others exposed to dioxins has produced a wide range of dermatological, metabolic, neurological, and behavioral effects [Huff et al, 1980]. The best known and most widely recognized of these is chloracne, which is often described as the "hallmark" of dioxin exposure. However, many of these other conditions can result from exposure without chloracne being present [May, 1973; Oliver, 1975; Pazderova-Vejlupkova et al, 1981].

These and other observations have led to the hypothesis that soldiers exposed to Agent Orange during military service in Vietnam are at increased risk for various acute and chronic diseases and for fathering children with birth defects.

Currently a number of studies are being conducted on the health of Vietnam veterans and their offspring. The majority are planned as long-term investigations and will not be completed for some years [American Medical Association, 1981]. A preliminary account of the Baseline Morbidity Study of Air Force personnel who conducted aerial herbicide dissemination missions in Vietnam (Operation Ranch Hand) showed no significant differences compared to control groups in conception outcomes such as prematurity, miscarriages, stillbirths, or "severe" birth defects but did observe an excess of "minor" defects as well as a significant excess of neonatal deaths and physical handicaps [Lathrop et al, 1984].

Among the studies now complete, a case-control study of babies born in the metropolitan Atlanta area concluded that Vietnam veterans in general did not have an increased risk of fathering babies with defects (all types combined) [Erickson et al, 1984a]. However, veterans judged to be "exposed" to Agent Orange had significantly higher risks of having children with birth defects including spina bifida, cleft lip with or without cleft palate, and a miscellaneous constellation of neoplasms. Donovan et al [1984] have reported that the risk for Australian Vietnam veterans to have fathered a child with a birth defect was no different from that of other Australian men.

In all these studies, one of the most difficult problems has been that of defining exposure. Accurate data on individual exposure is not available. Information on 
general herbicide usage exists but has so far proved difficult to translate into individual exposures.

Lathrop et al [1984, Chapter VIII] computed an average exposure index for each Ranch Hand subject by dividing the total gallonage of TCDD-containing herbicide sprayed in the entire Vietnam theater during the subject's tour of duty by the number of airmen with duties equivalent to that subject during the same time period. This measure does not take into account individual exposures at specific times and places.

Erickson et al [1984b] also used two different exposure indices. The first was a self-report obtained by asking the subject "Do you think you were ever exposed in any way to herbicides, like Agent Orange?" (p 228). A more objective "Exposure Opportunity Index" (EOI) was also developed, whereby a "panel of specialists familiar with existing records of herbicide spraying in Vietnam used a mixture of objective and subjective methods" to estimate possible exposures for individual veterans ( $p$ 23). Two separate EOI scorings were done, one based on occupation, location, and time recorded in military records ("records-based score") and one based on similar information obtained from direct interviews with the veterans ("interviewbased score"). Despite this incorporation of external information, the EOI scoring system was judged by authors of the study to be "a generally subjective evaluation." Furthermore, Erickson et al have commented that the mixture of effects reported could easily have resulted from errors of misclassification [Erickson et al, 1984a].

Thus there is a contrast between the highly technology-intensive techniques for evaluating the medical status of veterans and the less sophisticated methods of estimating exposure to herbicides developed to date. Despite these difficulties, however, one valuable source of objective, specific information on the patterns and extent of herbicide usage in Vietnam, the so-called HERBS tape, developed by the U.S. Army, can be useful in developing estimates of exposures. Indeed, this data source was used to derive the "records-based score" in the Atlanta birth defects study, although the exact way in which the information was incorporated into the EOI was not described [Erickson et al, 1984b, p 23].

The purpose of this paper is to investigate the use of the HERBS tape to see to what extent it can be a useful, objective source for exposure classification for individual veterans. The data file contained on this tape consists of an assembly of over 17,000 records, each describing a piece of an herbicide spray mission. The information provided within each tape record is summarized in Table I. Besides location, the tape records also contain data on dates of spraying, the type of mission, which of the three herbicides was used, the volume used, and the area sprayed. The

TABLE I. Data Contained on HERBS Tape

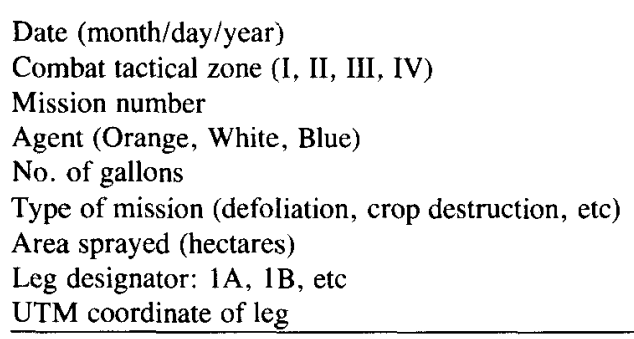


HERBS tape was kindly made available to us by the Records Management Group of the office of the Adjutant General of the U.S. Army.

\section{MATERIALS AND METHODS Resource: DoD HERBS Tape}

The 1980 version of the HERBS tape that we analyzed contained data on 6,475 distinct missions. A mission typically consisted of several legs, each one representing a continuous spray route, possibly including jogs. Each HERBS tape record refers to a single coordinate point on the map of Vietnam. Continuity of spray runs from point to point on the map (and from one HERBS tape record to the next) is indicated by letter-numeral combinations called leg designators (1A, 1B, etc). The numeral of the leg indicates the number of the run within the mission to which the associated coordinate belongs, and the letter designates the leg within that run. The coordinates are keyed to the Universal Transverse Mercator (UTM) system, which is a rectangular grid ruled off in 100,000-meter subgrids.

The diagram in Figure 1 shows two legs of a mission flown near Pleiku. The plane turned its spray on at $1 \mathrm{~A}$, and continued to spray as it flew on to $1 \mathrm{~B}, 1 \mathrm{C}, 1 \mathrm{D}$, $1 \mathrm{E}$, and $1 \mathrm{~F}$. It turned the spray off, flew to position $2 \mathrm{~A}$, and sprayed until $2 \mathrm{~B}$.

For our calculations, we used established coordinates of vertices only, rather than center-points or average locations, because low-flying spray planes were frequently fired on and forced to deviate from a straight-line course.

\section{Construction of Exposure Scales}

The method described here consists of several approaches used separately and in conjunction to provide different probabilistic exposure indices for the Vietnam veteran in question. The parts are 1) self-reported history by the veteran of the dates and locations he served in Vietnam as recorded in a precoded and tested Vietnam

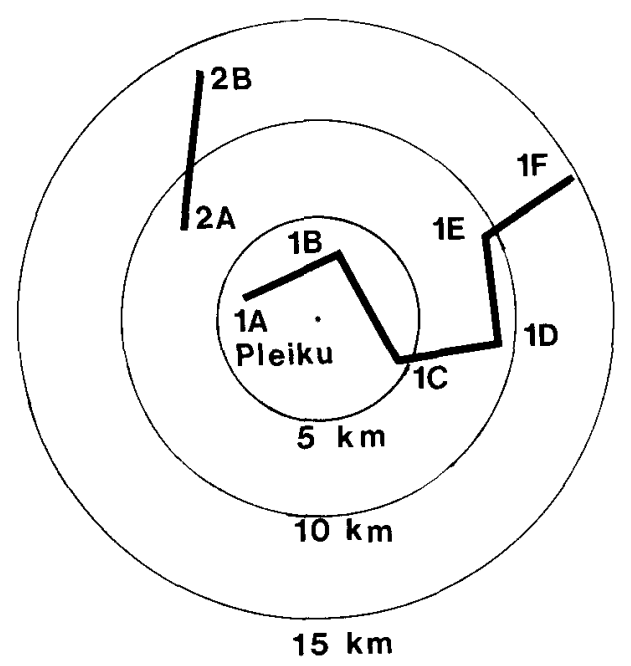

Fig. 1. Representation of a typical spray mission flown near Pleiku. Plane sprayed continuously from $1 \mathrm{~A}$ to IF, flew without spraying to $2 \mathrm{~A}$, then sprayed from $2 \mathrm{~A}$ to $2 \mathrm{~B}$. Number of vertices or "hits" falling within radii of 5,10 , and $15 \mathrm{~km}$ are 3,6 , and 8 , respectively. 
place-and-date matrix developed for this study, and described more fully below; 2) self-reported descriptions of military service, jobs, and experiences using a pretested, precoded questionnaire; 3 ) discrete exposure indices, $\mathrm{C}_{5}, \mathrm{C}_{10}, \mathrm{C}_{15}$, which are counts of the number of times a veteran was located within a specified radius $(5,10$, or 15 $\mathrm{km}$ ) from any of the spray locations on the HERBS tape, at times when spraying occurred; these indices incorporate information supplied by the veteran using the Vietnam place-and-date matrix; 4) continuous exposure indices: i) $\mathrm{E}_{1}$, a continuous distance-weighted measure of how close in distance to actual defoliation missions the veteran was during his tour of duty as calculated using the HERBS tape data and the veteran's military experience and place-and-date matrix; ii) $E_{2}$, an integrated estimate combining both direct exposure, as in i, and indirect exposure derived from residual herbicides, in an area of duty where spraying occurred prior to the veteran's service in that area, using the HERBS tape data and the veteran's place-and-date matrix; iii) $E_{3}$, an integrated exposure index combining both $i$ and ii above that allows for direct exposure, indirect exposure through environmental persistence, and distance from spraying missions during a veteran's tour of duty.

The discrete indices simply count the number of likely exposures that could have occurred within a specified radius of a veteran's location, whereas the continuous indices can take into account concurrent exposures plus potential exposures to residual herbicides from all previous spraying missions that took place within $15 \mathrm{~km}$ of a given location.

The continuous indices are defined by three related continuous exposure measures $\left(E_{1}-E_{3}\right)$. The first, represented by equation 1, defines the index of exposure, $\mathrm{E}_{1}$, as the sum of the reciprocals of the distances of all spray locations from a given position.

$$
\mathrm{E}_{1}=\mathrm{C}_{\mathrm{o}} \sum_{\mathrm{ij}}\left(1 / \mathrm{D}_{\mathrm{ij}}\right)
$$

where $\mathrm{C}_{\mathrm{o}}$ represents the initial concentration of the herbicide in each of the spraying missions, $\mathrm{D}_{\mathrm{ij}}$ is the distance from the veteran's ith known location to the jth coordinate on the tape, and $(i, j)$ pairs are restricted to those HERBS tape records $j$ whose dates coincide with the veteran's assignment dates at location $i$.

For the continuous index, $\mathrm{E}_{1}$, we only use spray dates included within the veteran's stay at location $i$, which do not include the effects of spraying during previous missions. The use of reciprocal distances in this index gives higher weight to closer "hits" in the summation. For computational convenience, the sum is restricted to all distances less than or equal to $15 \mathrm{~km}$; hits at greater distances contribute negligibly to the sum.

The second continuous measure of exposure, $E_{2}$, is given by equation $2 . E_{2}$ has been constructed to consider the environmental persistence of an exposure over time.

$$
E_{2}=C_{o} \sum_{i j} \int_{t_{1, i j}}^{t_{2, i j}} e^{-\lambda t} d t
$$

where $\lambda$ is a decay constant and $t$ is time. For an individual veteran, the expression in eq. 2 is integrated mathematically from $t=t_{1, i j}$ to $t=t_{2, i j}$, where $t_{1, i j}$ is the first date 
he was stationed at location $i$ and $t_{2, i j}$ is the date he left it. The integral is evaluated for each location $\mathrm{j}$ on the HERBS tape within $15 \mathrm{~km}$ of veteran location $\mathrm{i}$, provided the herbicide spraying occurred prior to $t_{2, i j}$. If the spraying occurred after time $t_{1, i j}$, then the lower limit of the integral is set to the actual date of spraying.

$E_{2}$ takes into account explicitly the fact that once sprayed Agent Orange and other herbicides will not instantaneously "disappear" but will be present in the environment and will be degraded as time passes. Therefore, the index $E_{2}$ gives higher weight to more recent sprayings while "remembering" past sprayings but weighting them according to an exponential decay law.

$A$ third index, $E_{3}$, given in equation 3 , is a composite of $E_{1}$ and $E_{2}$, which combines environmental persistence with reciprocal distance to give higher weight to more recent sprayings as well as to closer hits.

$$
E_{3}=C_{o} \sum_{i j}\left(1 / D_{i j}\right) \int_{t_{1, i j}}^{t_{2, i j}} e^{-\lambda t} d t,
$$

where the indices $i$ and $j$ and times $t_{1, i j}$ and $t_{2, i j}$, are as defined above. In these equations, we have assigned a constant concentration $C_{o}$ to the herbicide used in all missions.

For both $E_{2}$ and $E_{3}$, we have used a first-order exponential decay with rate constant $\lambda$. As with any first-order decay, the half-life, $\tau$, is given by

$$
\tau_{1 / 2}=\frac{\ln 2}{\lambda}
$$

The choice of a first-order decay law in the present study, that is, a constant half-life, is both an approximation and a conservative approach; it assumes a more rapid disappearance than might actually have occurred. Studies of environmental persistence of TCDD in soil surrounding Seveso, Italy, the site of a large-scale environmental release of TCDD, showed an increase in half-life with time [DiDomenico et al, 1980]. However, environmental degradation of TCDD in persistence studies conducted on heavily treated soils at test sites in Utah and Florida, observed by Young et al [1976], demonstrated decay consistent with first-order kinetics. In our calculations, we have assumed a half-life of 1 year, as suggested by several studies of TCDD persistence in soil [DiDomenico et al, 1980; Young et al, 1976; Kearny et al, 1972].

On the other hand, it might be that the total amount of herbicide reported sprayed during any one mission did not reach the ground because of jungle cover or otherwise was dispersed in the environment. For these reasons, this approach might overestimate exposure. However, in that these indexes are both probabilistic and relative, the use of the same kinetic equation for all troops should not introduce a systematic bias in any direction. Furthermore, ranking of veterans' exposure scores is insensitive to large changes in $\lambda$.

\section{Examples}

Two hypothetical examples of this calculation are shown in Figure 1 and in Table II. In the example of Figure 1, a veteran reported that he was present in Pleiku 
TABLE II. Number of Herbicide Spray "Hits" Within 5, 10, and 15 km of Six Selected Sites in Vietnam (1965-1971)

\begin{tabular}{|c|c|c|c|c|}
\hline \multirow[b]{2}{*}{$\underline{\text { Place }}$} & \multicolumn{3}{|c|}{ No. of spray hits within $(\mathrm{km})$} & \multirow{2}{*}{$\begin{array}{l}\text { Exposure } \\
\text { index } \mathrm{E}_{1}^{\mathrm{a}}\end{array}$} \\
\hline & 5 & 10 & 15 & \\
\hline Tay Ninh & 0 & 5 & 33 & 2.814 \\
\hline Chu Lai & 2 & 33 & 55 & 6.304 \\
\hline Khe Sanh & 15 & 23 & 55 & 8.264 \\
\hline Camp Evans & 3 & 35 & 110 & 10.609 \\
\hline Phuoc Vinh & 27 & 144 & 356 & 38.958 \\
\hline Pleiku & 69 & 74 & 121 & 43.600 \\
\hline
\end{tabular}

${ }^{\mathrm{a}}$ Defined by eq 1 .

on the date the diagrammed spray mission took place. As is shown in the figure, three vertices fall within $5 \mathrm{~km}$ of Pleiku, six fall within $10 \mathrm{~km}$, and all eight fall within 15 $\mathrm{km}$. We call these counts the "number of hits within 5,10 , and $15 \mathrm{~km}$," respectively, and our scheme assigns the veteran exposures $C_{5}=3, C_{10}=6$, and $C_{15}=8$ for this particular mission. This type of count can be computed for any location in Vietnam whose UTM coordinates are known.

As a second example, we have summed the indices $\mathrm{C}_{5}, \mathrm{C}_{10}$, and $\mathrm{C}_{15}$, which count the total number of "hits" within specific radii, in six towns or other places in Vietnam, where thousands of American troops were stationed: Chu Lai, Khe Sanh, Camp Evans, Pleiku, Tay Ninh, and Phuoc Vinh. Table II shows the total number of such hits falling within 5,10 , and $15 \mathrm{~km}$ of these locations, respectively, as well as the total index, $E_{1}$, derived from all sprayings from 1965 through 1971 . These represent upper limits to exposure indexes that would be calculated for veterans stationed at these locations for shorter periods of time. These sample calculations illustrate how the indices can differentiate exposure classification among combat troops.

\section{Self-Reported Location and Exposure Data}

Self-reported history and place-and-date matrix formats were developed in consultation with numerous veterans and other experts on Vietnam geography. A matrix, divided into the four Combat Tactical Zones, or Corps, in Vietnam, I, II, III, and IV, was created in which major villages, locations, and areas heavily used by American troops were listed by the names used by the veterans. The printed matrix was accompanied by a map of Vietnam on which larger towns were also shown. The matrix was designed so that the respondent could indicate up to 98 specific places in Vietnam where he might have served and the dates that he was there.

This method of collecting location and date information data was pretested in 100 California veterans and proved to be a satisfactory data collection instrument. Approximately $70 \%$ of questionnaires had sufficiently completed places and dates to calculate the above exposure measures without assistance and without an interview. The questions used in the self-described exposure section are reproduced in Table III.

Subjects were asked whether they had experienced any of the following: been a sprayer on a C-123, helicopter, or boat; had worked at clearing vegetation; had worked as a sprayer or handler of herbicides during shipment; or had slept in or walked through obviously defoliated areas. Subjects were then classified as "ex- 


\section{TABLE III. Wording of Questions on Self-Described Exposure to Agent Orange}

In this section we are interested in finding what you remember about being exposed to defoliating herbicides, such as Agent Orange, which were used to kill jungle cover in Southeast Asia. If you believe you were exposed to such a chemical agent, either by directly loading it, spraying it, or entering a freshly sprayed area, we would like you to describe how you were exposed and when.

If you don't remember being directly exposed to herbicides, check here: and go on to next page.

\begin{tabular}{|c|c|c|c|}
\hline & No & Yes & $\begin{array}{l}\text { If yes, } \\
\text { No. of } \\
\text { weeks }\end{array}$ \\
\hline Sprayer on C- 123 & - & - & - \\
\hline Sprayer on helicopter & - & - & - \\
\hline Sprayer on boat & - & - & - \\
\hline $\begin{array}{l}\text { Loader/handler of spray on any } \\
\text { of the above }\end{array}$ & - & - & - \\
\hline $\begin{array}{l}\text { Job involved clearing vegetation } \\
\text { and/or patrolling around camp, } \\
\text { roads, or clearing free-fire } \\
\text { zones }\end{array}$ & - & - & - \\
\hline $\begin{array}{l}\text { Slept/walked through sprayed } \\
\text { areas. Exposed to herbicides } \\
\text { used near camp or on roads } \\
\text { you traveled on }\end{array}$ & - & - & - \\
\hline $\begin{array}{l}\text { Handler of spray during storage } \\
\text { or shipment }\end{array}$ & - & - & - \\
\hline
\end{tabular}

posed" or "not exposed" to each of these spray occupations or to recently sprayed terrain.

This information allowed us to compare the measures of exposure derived from the HERBS tape against the observations, experiences, and military jobs reported by the soldiers.

\section{Application of Algorithms and Analysis of HERBS Tape}

We have tested the exposure indices on a sample of 478 veterans selected from a study we have been conducting with the Veterans Education Project of the National Veterans Law Center, American University. Several thousand questionnaires were mailed to veterans participating in a nationwide outreach program sponsored by the Veterans Education Project. The questionnaires solicited information on veterans' health and reproductive outcomes and contained the exposure instruments described above. This sample was clearly highly self-selected, so that it would not be appropriate to generalize directly associations of herbicide exposures with health outcomes from this population to all Vietnam veterans. However, because our present purpose is only to investigate our proposed exposure indices, and not health outcomes, there is nothing inherently biased in using this group to test the exposure algorithms, of which the respondents had no knowledge. This point is discussed again below.

Finally, we have also carried out calculations on the aggregated data contained in the HERBS tape to obtain additional data on overall usage of defoliants and hence to provide more information about potential exposure of American troops in Vietnam during 1965-1971. In addition, we have made estimates of the relative concentration of herbicides used on each of the missions by calculating the ratio of gallons to area sprayed using the data recorded on the tapes. 


\section{RESULTS}

\section{Overall Patterns and Extent of Defoliation Activities}

Quantities of herbicides recorded on the HERBS tape can be compared to previously published estimates of herbicide use in Vietnam as an indicator of the completeness of data available to us. The total volume of Agent Orange recorded on the HERBS tape was $11,197,929$ gallons, which differs by less than $0.7 \%$ from the quantity reported by the National Academy of Sciences [Committee on the Effects of Herbicides in South Vietnam, 1974]. Similar levels of agreement were observed for Agents Blue and White.

Defoliants were used in Vietnam for a variety of purposes. Figure 2 shows the major reported uses of the three herbicides in Vietnam, defoliation and crop destruction; Figure 3 shows the minor uses reported, related to Vietnamese troop movement and their interdiction. More than 10 million gallons of Agent Orange were sprayed in at least 3,000 separate defoliation missions. Nearly another million gallons of Agent Orange were used in crop-destruction programs. About 5 million gallons of Agent White and 1 million gallons of Agent Blue were also used for these purposes. Approximately 100,000 gallons of Agent Orange were sprayed around the perimeters of bases to deny cover to enemy troops. These latter uses of defoliants might also have led to significant exposure to U.S. troops.

For more than $80 \%$ of the missions, the calculated ratio of gallonage to area sprayed, which is a close approximation of concentration, is nearly constant. Fifteen percent of the missions with a substantially different gallon/area ratio occur among

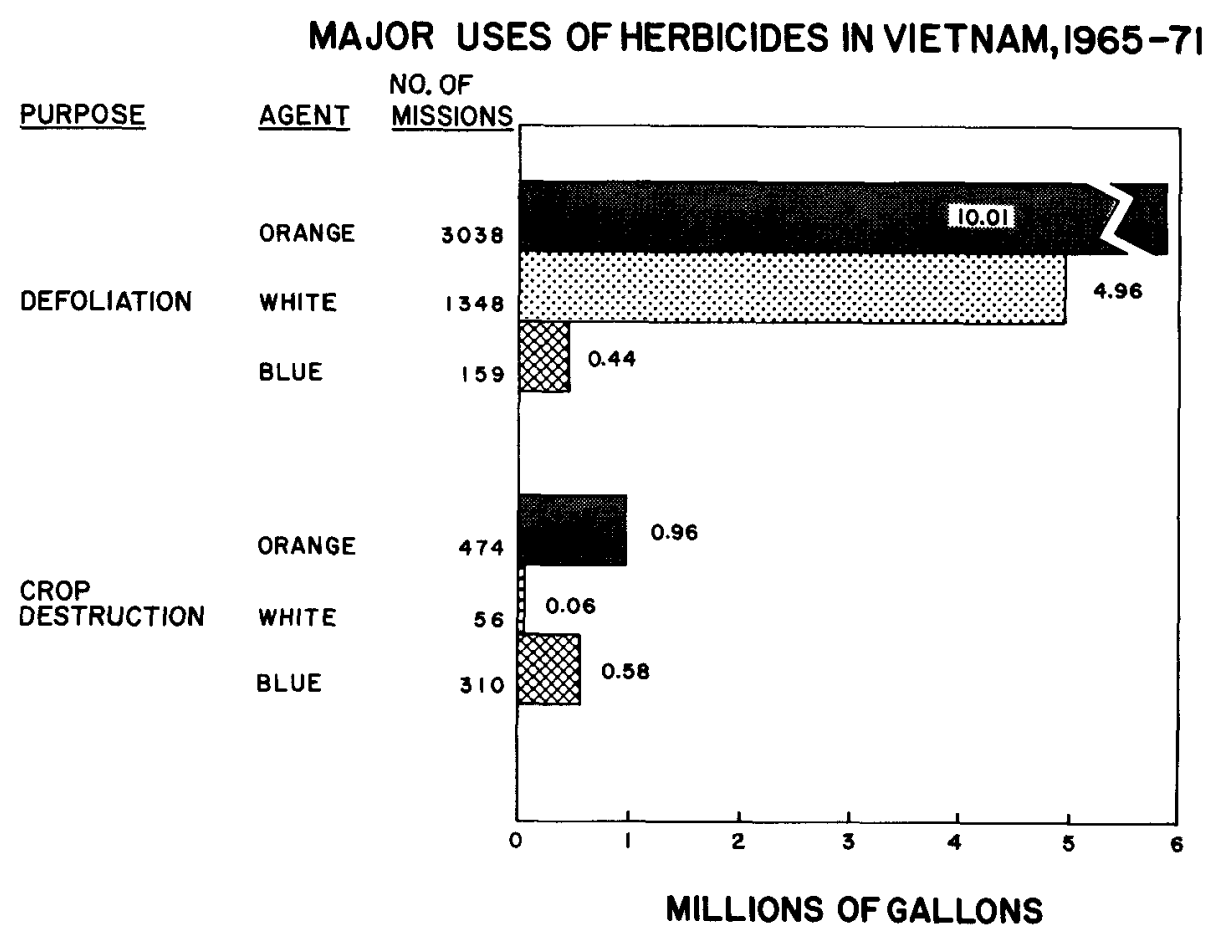

Fig. 2. Quantities of Agents Orange, White, and Blue used in defoliation and crop destruction missions in South Vietnam, 1965-1971. 


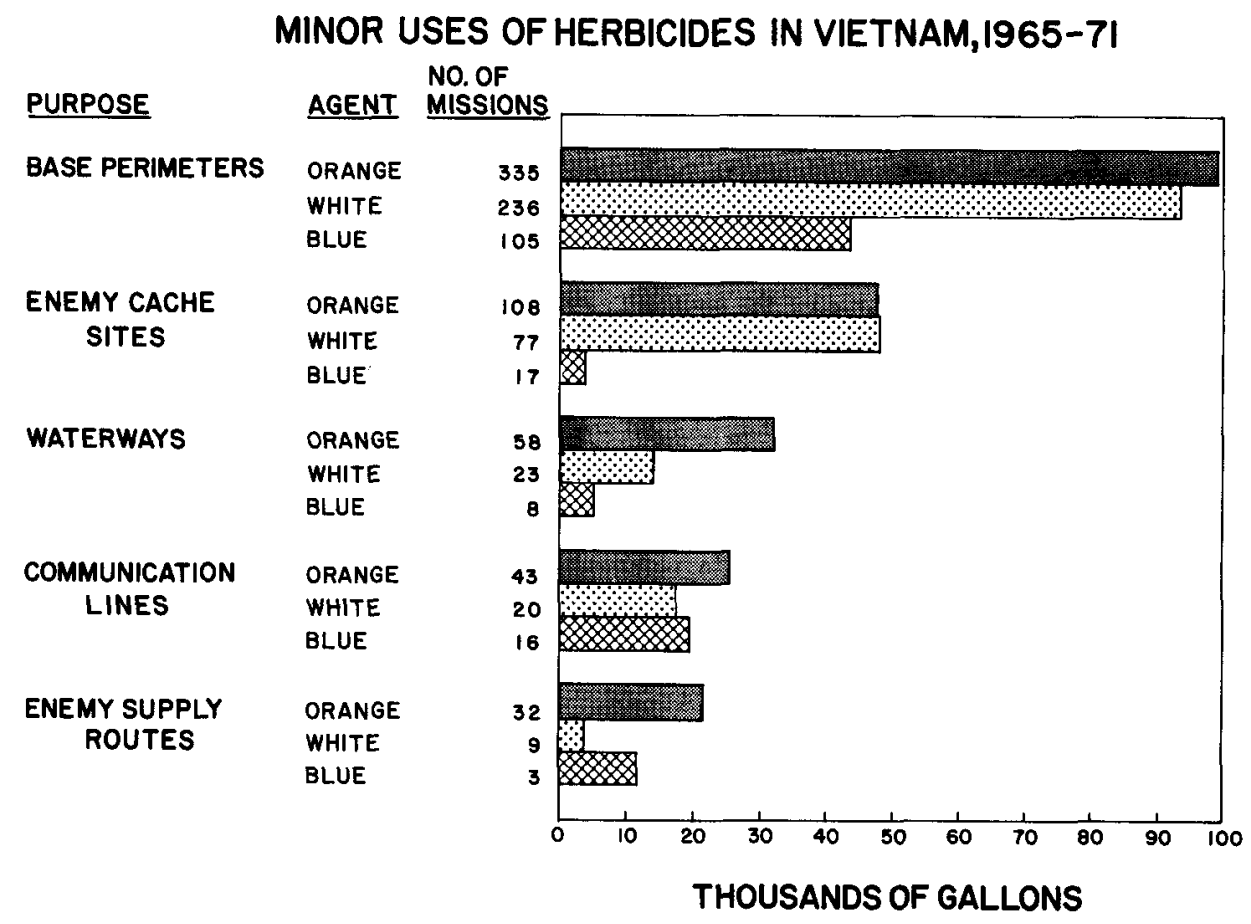

Fig. 3. Quantities of Agents Orange, White, and Blue used in five minor types of missions in South Vietnam, 1965-1971.

missions in the lowest gallonage classification ( $<500$ gallons), and $5 \%$ of the missions dispensed less than 100 gallons.

Although herbicide use in Vietnam had begun by January, 1962, the HERBS tape covers only those spray missions conducted after June, 1965. Limited amounts ( $<300,000$ gallons) of other dioxin-contaminated herbicides, notably Agents Pink and Purple (active ingredient 2,4,5-T), were disseminated between January, 1962, and December, 1964 [Young et al, 1978]. In that these were years before major American troop involvement, the number of U.S. servicemen exposed would be extremely small. Figure 4 shows the total herbicide usage by calendar quarter. The precipitous drop in the first quarter of 1968 coincides with the Tet Offensive. As is indicated in the figure, usage tended to be most widespread when the largest numbers of U.S. soldiers were in the field. However, the extent of direct spraying on troops has not been established, and Armed Services experts contend that spraying occurred well in advance of anticipated troop movements into target areas (G. Lathrop, personal communication).

\section{Herbicide Exposure Probability Indexes Among 478 Vietnam Veterans}

Equations 1-4 were applied to our study population. Of the 543 men sampled, 478 had sufficient information to compute exposure indices, and 303 of these judged themselves "exposed" within at least one of the categories queried in Table III. Mean scores for the various discrete and continuous scales were computed separately for men designated as "exposed" either by holding a military job with exposure or by reporting themselves to have been in contact situations as well as for the remaining 
HERBICIDE USE IN VIETNAM,|965-I97|

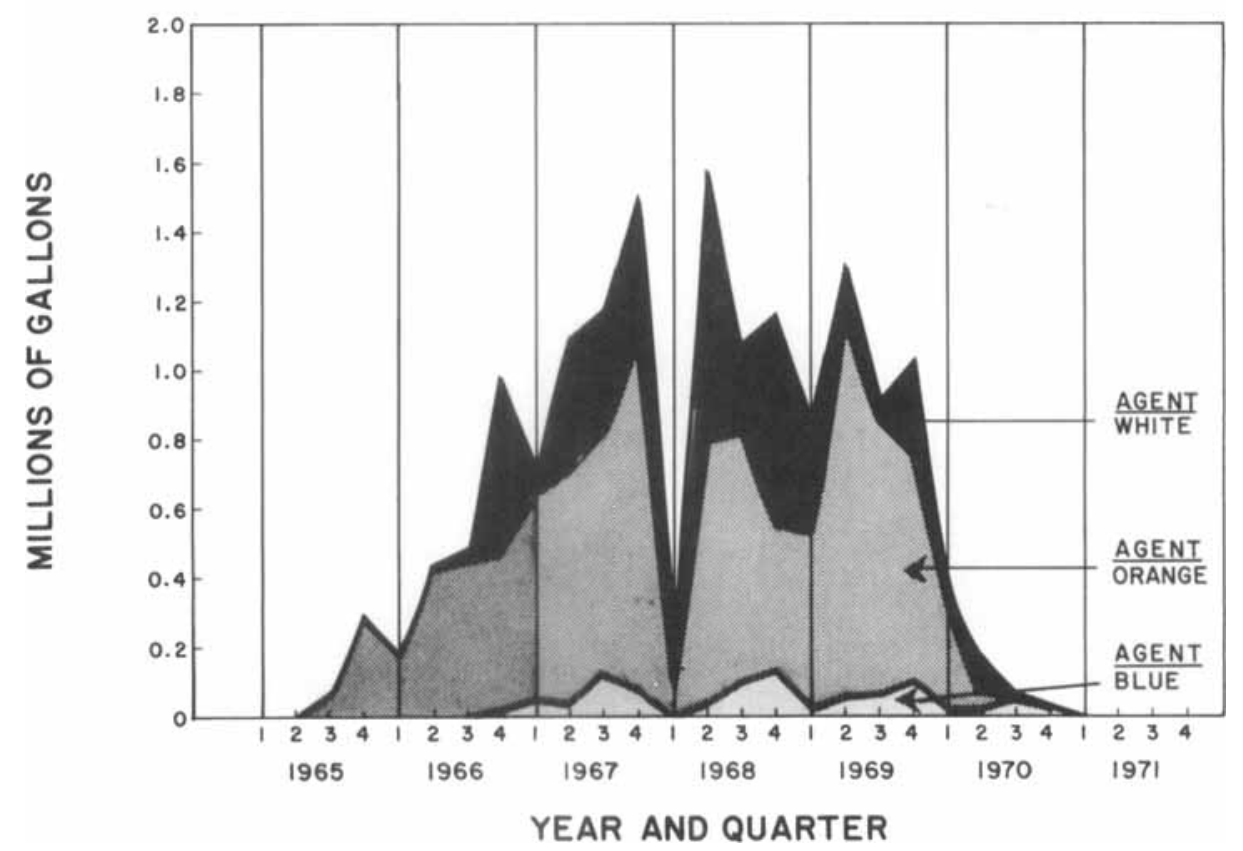

Fig. 4. Quantities of three herbicides used in South Vietnam, 1965-1971, by calendar quarter.

group of 175 men who said they did not think they were exposed and who did not indicate that they had held any of the likely exposure jobs. Results are shown in Figure 5. All six of the "exposed" groups had both $\mathrm{C}_{15}$ and $\mathrm{E}_{3}$ means higher than the mean of the "unexposed" group, and all categories but one (shipping handlers, a group for which we had few observations) had more "hits within $15 \mathrm{~km}$," $\mathrm{C}_{15}$, than the population average for that variable.

In that a number of men belong to more than one nominally "exposed" category, the groups are not independent, so it is not meaningful to make statistical comparisons between the group means. However, the mean values of the discrete exposure index, $\mathrm{C}_{15}$, as well as of the continuous indices $\mathrm{E}_{1}, \mathrm{E}_{2}$, and $\mathrm{E}_{3}$, in exposed and unexposed groups as a whole are compared in Table IV. Mean values for $E_{2}$ and $E_{3}$ were significantly higher in the exposed compared to the unexposed: mean $\mathrm{E}_{2}$ was $41 \%$ higher $(\mathrm{p}<.01)$ and mean $\mathrm{E}_{3}$ was $32 \%$ higher in the exposed. Using a MannWhitney $\mathrm{U}$ test for the discrete variable $\mathrm{C}_{15}$, the mean rank among the exposed was significantly higher than in the unexposed $(\mathrm{p}<.05)$.

\section{DISCUSSION}

These indexes have been developed expressly for the purpose of assigning probabilities of exposure to herbicides in epidemiological studies of large numbers of veterans and are not claimed to represent actual exposures perfectly. They are to be regarded as approximations to population exposures in the same sense that past exposures to dusts and chemicals are often estimated for workers in industries for 

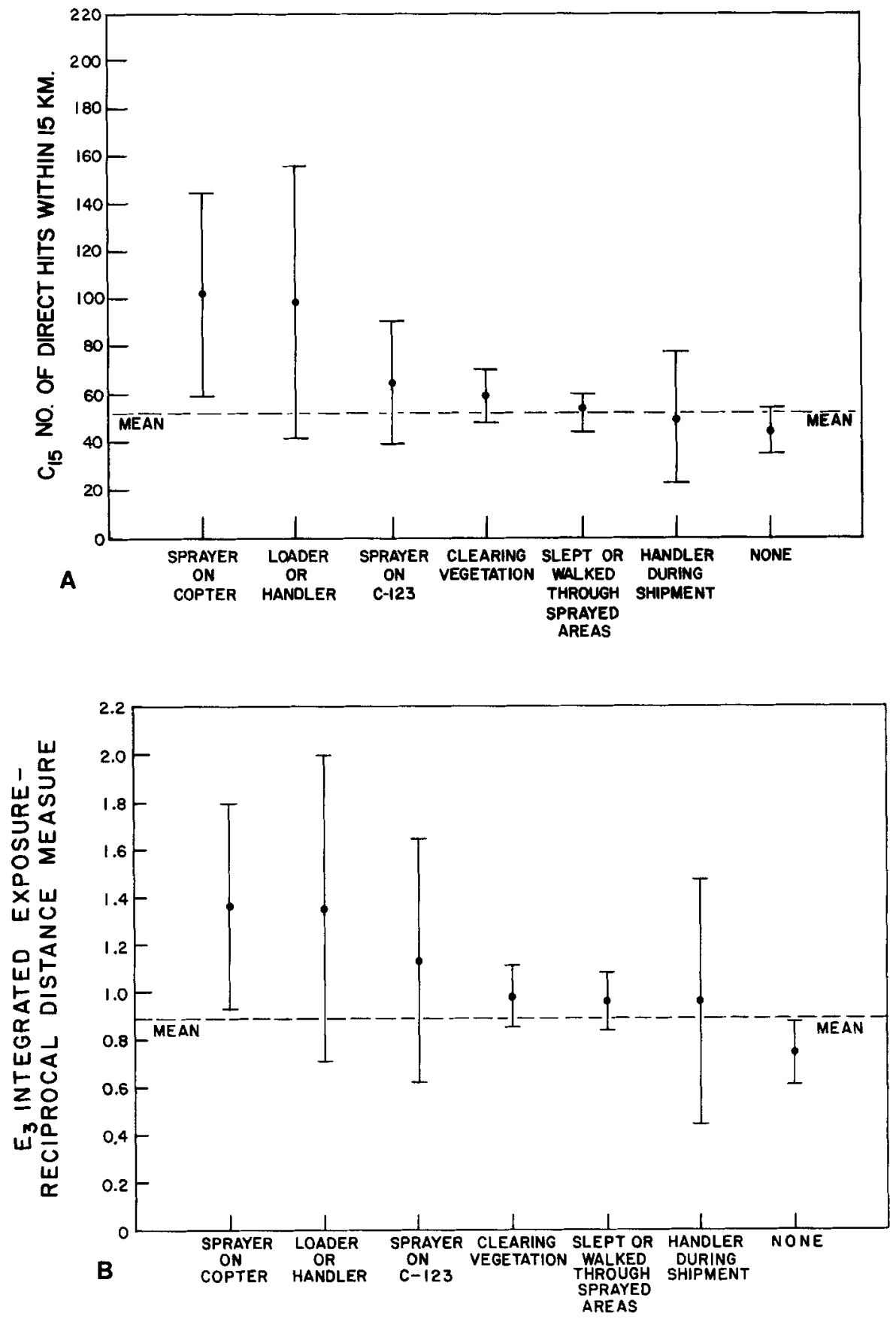

Fig. 5. A, mean discrete exposure index $\mathrm{C}_{15}$ computed for men with six different job categories with probable Agent Orange exposure and for men not likely to have been exposed. B, same for continuous exposure index $\mathrm{E}_{3}$. 
TABLE IV. Statistical Comparisons Between Mean Exposure Indices for Veterans Self-Described as "Exposed" and "Not Exposed" to Agent Orange

\begin{tabular}{lccc}
\hline Variable & $\begin{array}{c}\text { Average value of } \\
\text { variable for } \\
\text { veterans reporting } \\
\text { exposure }\end{array}$ & $\begin{array}{c}\text { Average value of } \\
\text { variable for } \\
\text { veterans not } \\
\text { reporting exposure }\end{array}$ & $\mathrm{p}$ \\
\hline $\mathrm{E}_{1}$ & $8.94(303)^{\mathrm{a}}$ & $8.39(175)$ & $\mathrm{NS}$ \\
$\mathrm{E}_{2}$ & $8.25(303)$ & $5.85(175)$ & $<.01$ \\
$\mathrm{E}_{3}$ & $0.98(303)$ & $0.74(175)$ & $<.05$ \\
\hline
\end{tabular}

\begin{tabular}{ccccc}
$\begin{array}{c}\text { Mean } \\
\text { rank }\end{array}$ & $\begin{array}{c}\text { Mean } \\
\text { rank }\end{array}$ & $\begin{array}{c}\text { Mann- } \\
\text { Whitney } \\
\mathrm{U}\end{array}$ & $\mathrm{U}$ \\
\hline $\mathrm{C}_{15}$ & $248.9(303)$ & $223.2(175)$ & $2,364.5$ & $<.05$ \\
\hline
\end{tabular}

${ }^{a}$ Numbers of veterans are given in parentheses. NS, not significant.

which industrial hygiene measurements of past conditions are not available. As approximations, it is important to bear in mind their limitations. The HERBS tape itself is incomplete, particularly with respect to base perimeter spraying and jettisoning of some plane loads. Data on individual veterans are limited by their recall and personal records. Towns in Vietnam near where veterans were stationed are used as surrogates for actual coordinates of their unit locations. Computed exposures will thus tend to underestimate true exposures, and risk assessments will therefore be biased conservatively, ie, towards finding no association. Within these limitations, distributions of the indexes are sufficiently broad to permit comparative categorization of exposure.

As is illustrated in Figure 5 and Table IV, HERBS tape-derived exposure indices vary widely among individual troops, ranging from no exposure to a high probability of having been directly sprayed upon, and are consistent with likely exposures associated with specific military jobs and experiences in Vietnam.

It is particularly noteworthy that there is little difference in mean $E_{3}$ values for men whose self-reports indicated that they cleared vegetation or slept or walked through fields, and men who reported no exposure. We believe this to be reflective of the uncertainty and confusion that exists in the minds of many veterans about whether they were exposed to Agent Orange. Many sources of defoliation in Vietnam in addition to chemical herbicides have been documented by the National Academy of Sciences [Committee on the Effects of Herbicides in South Vietnam, 1974], such as bombing and shelling, use of Rome plows (super-bulldozers), resettlement, cutting of trees for lumber and firewood, and local agricultural practices (swidden agriculture); it is difficult to see how a soldier under the stress of combat could be expected to distinguish one cause of defoliation from another. In addition, men might have been purposefully sprayed from the air with malathion for mosquito control and might have mistaken this spraying activity as a herbicide defoliation mission (G. Lathrop, personal communication).

Our method can sort out those individuals who erroneously believe themselves to have been exposed and whose misclassification might thereby dilute any potentially observable effect in an epidemiological study. On the other hand, a self-report might 
miss important sources of contact with defoliants because the soldier was unaware of previous spraying in the area. Note, for example, the statistically significant differences in $E_{2}$ and $E_{3}$ between groups in Table IV, which take into account prior spraying at a given location, compared to the lack of statistical significance of differences among values for $E_{1}$, which includes only current exposure. This demonstrates the importance of considering the residual effects of herbicide spraying encountered by troops long after the actual date of herbicide application, even though the exact rates of decay are not known.

In a previous survey of veterans [Stellman and Stellman, 1980], we recorded reports of hundreds of servicemen who had entered freshly denuded forests and who camped within defoliated areas, either in the jungle or near the perimeters of their base camps, in areas that were recently sprayed. In addition, men could have been exposed by spending time in areas long after spraying took place. Men on extended jungle patrols often swam in and drank water from streams that drained defoliated areas. The possibility of exposure from the latter source cannot be ruled out. Tissue samples from rodents, birds, fish, and reptiles trapped several years after spray tests were halted at a Florida test site for Agent Orange (Table V) contained traces of dioxin [Young et al, 1978, Chapter III, p 19].

It is precisely for these reasons that it is impossible to give credence to any health effects study in which assignment of herbicide exposure levels to individual veterans is based solely on self-reports.

We are aware, of course, of limitations associated with surveys of self-selected individuals. In health surveys, subjects can be self-selected for a variety of reasons, including concern over possible exposure to Agent Orange and concern about their own health. For this reason, any studies relating exposures to health outcomes in this population are likely to be highly biased. However, insofar as no veteran could possibly know the thousands of dates and places of missions on the tape, there can be very little selection bias in this measure. Even were a veteran to know which locations were highly publicized "hot spots," he would have to report his presence there at the right time to achieve a high score. In this study, one of our quality control procedures entails editing of all subject-reported dates at specific Vietnam locations against his

TABLE V. Levels of TCDD Found in Animals 3-8 Years After Heavy Spraying of Agent Orange at Eglin Air Force Base, Florida [Young et al, 1978]

\begin{tabular}{llc}
\hline Species & \multicolumn{1}{c}{ Tissue } & $\begin{array}{c}\text { Concentration } \\
\text { (ppt) }\end{array}$ \\
\hline Mammals & & \\
$\quad$ Beachmouse & Liver & $300-2400$ \\
Hispid cotton rat & Liver & $<10-210$ \\
Birds & & \\
$\quad$ Meadowlark & Liver & $100-1020$ \\
Mourning dove & Liver & 50 \\
Savannah sparrow & Liver & 69 \\
Fish & & 86 \\
Spotted sunfish & Liver & 12 \\
Mosquito fish & Whole body & 12 \\
Sailfin shiner & Whole body & $360-430$ \\
Amphibia & & \\
Six-lined racerunner & Muscle & \\
\hline
\end{tabular}


dates of Southeast Asia service and overall military service. More elaborate checks against external sources are also possible, although the expense might be considerable. We believe little if any such fabrication has occurred in this study.

Therefore, we believe this to be an independent and objective source of exposure information, despite the fact that our data were elicited from participants who selected themselves to participate in our survey. Furthermore, from the wide variability of the aggregated indices for these specific locations, we infer that it would be quite difficult for a subject to deliberately fabricate a high score for himself. That is, a subject is highly unlikely to be able to identify places at random and expect that the scores for those places, restricted to the time period he served in Vietnam, would be especially high.

Because questionnaires are all self-administered, there is the usual problem of how to handle missing or obviously incorrect information. Our evaluation algorithms are biased towards minimizing exposure by truncating Vietnam location dates according to overall dates of service in Vietnam and eliminating records with no dates at all, The majority of respondents took great pains to fill out the exposure-related section and the Vietnam location and date section with care. Fewer than five questionnaires from obviously unreliable subjects were eliminated. Recent experience with another, nonself-selected group, comprising a random sample of several state membership lists of the American Legion, convinces us that veterans possess and utilize many resources to recall just where they were in Vietnam and what they did there [Stellman and Stellman, 1985].

A still more accurate exposure method would, in addition, assign different exposure values to each mission according to the actual number of gallons dispersed, the area sprayed, the rate of dispersion, and even the meteorological conditions, if these data were available. For the great majority of missions, the results obtained here would not change, because, as indicated above, the ratio of gallons to area was nearly constant. Without taking differing concentrations into account, the method is, at worst, a conservative approach to exposure estimation, because the small number of concentration outliers are concentrated in the missions carried out over the smallest acreage, hence possibly representing the most intense exposure.

There is, of course, the problem of incomplete or incorrect data on the HERBS tape itself. It is probable that we are underestimating exposure arising from backpacking and other small but intense uses of herbicides; we know that most of the missions with a substantially different gallons/area ratio from the calculated average fall in the low-gallonage category. Refinement of the method, with variations in concentration and in different types of spray missions taken into account, is currently underway. The U.S. Army is revising the 1980 HERBS tape to provide still more accurate data on backpacking missions. This new information will be incorporated into our method as soon as it becomes available.*

It might, of course, be possible for other researchers, particularly those engaged in large, government-sponsored studies, to obtain complete military records of troop movements in Vietnam, as has been attempted by Erickson et al [1984b], and to apply this or similar methods to derive still more accurate exposure information, thereby possibly eliminating many of the drawbacks associated with personal recall and use

*Note added in proof: The Army Records Management Group released a supplemental tape containing such records in September, 1985. These will be incorporated into our future reports. 
of self-administered questionnaires and approximations of concentration. On a more modest level, the method outlined in this article can be readily applied at minimal expense by the many registries and projects now being carried out by state agencies and private research groups.

The obvious next step is to examine the prevalence of adverse health conditions in relation to the values of the herbicide exposure indexes described in this paper. Such studies are now in progress. Although there will, of necessity, be shortcomings in any system attempting to classify the probability and extent of exposure to herbicides in Vietnam, because of the passage of time as well as inherent uncertainties in the actual amount of defoliant to reach the ground and come in contact with troops, the system proposed here is a mathematically defensible approach using an extensive and unique data base, the HERBS tape, which assigns probabilistic exposures to troops in an objective and impartial way.

\section{ACKNOWLEDGMENTS}

This study was made possible through the help of many individuals and institutions: Lawrence Garfinkel, American Cancer Society; John Jordan, Louise Ransom, Robert Morris, Andy Smith, Tim Smith, and Chris Iosso, National Council of Churches; Keith Snyder, Lew Milford, and Ron Simon, National Veterans Law Center, American University; Mike Gold, City University of New York Department of Veterans Affairs; Stephen Zoloth and David Kotelchuck, Hunter College of the City University of New York; John F. Sommer, Jr., The American Legion; and Richard Christian, U.S. Army Records Management Group.

This work was partially supported by U.S. Public Health Service grant NCI 5K07-CA-00730 (J.M.S.) and by a special grant from the National Council of Churches.

\section{REFERENCES}

American Medical Association (1981): "The Health Effects of 'Agent Orange' and Polychlorinated Dioxin Contaminants (Technical Report)." Chicago: Council on Scientific Affairs.

Collins TFX, Williams CH (1971): Teratogenic studies with 2,4,5-T and 2,4-D in the hamster. Bull Environ Contam Toxicol 6:559-567.

Committee on the Effects of Herbicides in South Vietnam (1974): "Part A. Summary and Conclusions." Washington, DC: National Academy of Sciences.

Courtney KD, Moore JA (1971): Teratology studies with 2,4,5-trichlorophenoxyacetic acid and 2,3,7,8tetrachlorodibenzo-p-dioxin. Toxicol Appl Pharmacol 20:396-403.

DiDomenico A, Silano V, Viviano G, Zapponi G (1980): Accidental release of 2,3,7,8-tetrachlorodibenzo-p-dioxin (TCDD) at Seveso, Italy. V. Environmental persistence of TCDD in soil. Ecotoxicol Environ Safety 4:339-345.

Donovan JW, MacLennan R, Adena M (1984): Vietnam service and the risk of congenital anomalies. A case-control study. Med J Australia 140:394-397.

Erickson JD, Mulinare J, McClain PW, Fitch TG, James LM, McClearn AB, Adams MJ (1984a): Vietnam veterans' risks for fathering babies with birth defects. JAMA 252:903-912.

Erickson JD, Mulinare J, McClain PW, Fitch TG, James LM, McClearn AB, Adams MJ (1984b): "Vietnam Veterans' Risks for Fathering Babies With Birth Defects." Atlanta: Centers for Disease Control.

Fenton BK (1984): A fatal case of 2,4-D toxicity? Vet Rec, June 16, 1984, p 599.

Goldstein NP, Jones PH, Brown JR (1959): Peripheral neuropathy after exposure to an ester of dichlorophenoxyacetic acid. JAMA 171:1306-1309. 
Grant WF (1979): The genotoxic effects of 2,4,5-T. Mutat Res 65:83-119.

Hood RD, Patterson BL, Thacker GT, Sloan GL, Szczech GM (1979): Prenatal effects of 2,4,5-T, 2,4,5trichlorophenol, and phenoxyacetic acid in mice. J Environ Sci Health C13:189-204.

Huff JE, Moore JA, Saracci R, Tomatis L (1980): Long-term hazards of polychlorinated dibenzodioxins and polychlorinated dibenzofurans. Environ Health Perspect 36:221-240.

International Agency for Research on Cancer (1977): Some fumigants, the herbicides 2,4-D and 2,4,5T, chlorinated dibenzodioxins and miscellaneous industrial chemicals. In: "IARC Monograph 15: Evaluation of the Carcinogenic Risk of Chemicals to Man." Lyon: IARC.

Kearny PC, Woolson EA, Ellington CP Jr (1972): Persistence and metabolism of chlorodioxins in soils. Environ Sci Technol 6:1017-1019.

Kociba RJ, Keyes DG, Beyer JE, Carreon RM, Wade CE, Dittenber DA, Kalnins RP, Frauson LE, Park CN, Barnard SD, Hummel RA, Humiston CG (1978): Results of a two-year chronic toxicity and oncogenicity study of 2,3,7,8-tetrachlorodibenzo-p-dioxin in rats. Toxicol Appl Pharmacol 46:279-303.

Lathrop GD, Wolfe WH, Albanese RA, Moynahan PM (1984): “An Epidemiologic Investigation of Health Effects in Air Force Personnel Following Exposure to Herbicides. Baseline Morbidity Study Results." Brooks Air Force Base: USAF School of Aerospace Medicine.

May G (1973): Chloracne from the accidental production of tetrachlorodibenzodioxin. Br J Indust Med 30:276-283.

Neubert D, Dillmann I (1972): Embryotoxic effects in mice treated with 2,4,5-trichlorophenoxyacetic acid and 2,3,7,8-tetrachlorodibenzo-p-dioxin. Arch Pharmacol 272:243-264.

Oliver RM (1975): Toxic effects of 2,3,7,8-tetrachlorodibenzo-1,4-dioxin in laboratory workers. $\mathrm{Br} \mathrm{J}$ Indust Med 32:49-53.

Pazderova-Vejlupkova J, Nemcova M, Pickova J, Jirasek L, Lukas E (1981): The development and prognosis of chronic intoxication by tetrachlorodibenzo-p-dioxin in men. Arch Environ Health 36:5-11.

Rowe VK, Hymas TA (1954): Summary of toxicological information on 2,4-D and 2,4,5-T type herbicides and an evaluation of the hazards to livestock associated with their use. Am J Vet Res $15: 622-629$

Schwetz BA, Sparschu GL, Gehring PJ (1971): The effect of 2,4-dichlorophenoxyacetic acid (2,4-D) and ester of 2,4-D on rat embryonal, foetal and neonatal growth and development. Food Cosmet Toxicol 9:801-817.

Schwetz BA, Norris JM, Sparschu GL, Rowe VK, Gehring PJ, Emerson JL, Gerbig CG (1973): Toxicology of chlorinated dibenzo-p-dioxins. Environ Health Perspect 5:87-99.

Stellman SD, Stellman JM (1980): Health problems among 535 Vietnam veterans potentially exposed to toxic herbicides. Paper presented at the Society for Epidemiologic Research, Minneapolis, June, 1980.

Stellman JM, Stellman SD (1985): "Columbia University-American Legion Vietnam Veterans Study. Report No. 1, May 29, 1985." Washington, D.C.: The American Legion.

Van Miller JP, Lalich JJ, Allen JR (1977): Increased incidence of neoplasms in rats exposed to low levels of 2,3,7,8-tetrachlorodibenzo-p-dioxin. Chemosphere 9:537-544.

Young AL, Thalken CE, Arnold EL, Cupello JM, Cockerham LG (1976): "Fate of 2,3,7,8-Tetrachlorodibenzo-p-Dioxin (TCDD) in the Environment: Summary and Decontamination Recommendations (USAFA-TR-76-18)." U.S. Air Force Academy, Colorado: Department of Chemistry and Biological Sciences.

Young AL, Calcagani JA, Thalken CE, Tremblay JW (1978): "The Toxicology, Environmental Fate and Human Risk of Herbicide Orange and Its Associated Dioxin (USAF Occupational and Environmental Health Laboratory (OEHL), Technical Report No. TR-78-92, Final Report)." Brooks Air Force Base, Texas: Medical Division. 